\title{
A busca da informação por parte de entidades representativas
}

\author{
Dulce Maria Baptista \\ Formada em letras pela PUC/Rio e em biblioteconomia pela UnB. \\ Mestre em educação e doutora em ciência da informação pela UnB. \\ Atualmente, Information Assistant, Information Resource Center, \\ Embaixada Americana em Brasília. E-mail dmbbsb@pd.state.gov
}

\section{Resumo}

Pesquisa destinada a investigar as necessidades de informação, bem como formas e mecanismos de sua obtenção por parte de entidades representativas brasileiras em sua qualidade de formadoras de opinião. A amostra estudada compôs-se de nove entidades voltadas à representação das seguintes categorias e setores da sociedade: indústria, setor bancário, educação, trabalhadores, mulheres, cultura negra e consumidores. Para a coleta de dados foi utilizada a triangulação de técnicas, com realização de entrevistas informais, aplicação de questionário e análise documental. Os resultados revelam que as fontes impressas têm, para as entidades, a mesma importância que a Internet; a comunicação informal não constitui o principal recurso informacional; existem convergências tanto em termos de necessidades de informação, como em termos do comportamento adotado pelas entidades ao buscarem a informação de seu interesse.

\section{Palavras-chave}

Formação de opinião; Fontes de informação; Entidades representativas; Gerência da informação.

\begin{abstract}
Investigation of information needs as well as of forms and mechanisms for its procurement by representative institutions in their role of opinion makers. A sample of nine institutions was selected for the study, being it related to the following sectors: industry, education, unions, labor, banking, women, black culture and consumers. Triangulation was used as a means for collecting data, with complementary use of informal interviews, questionnaire and document analysis. The results show that to the studied entities, paper sources and Internet are equally important; informal communication does not constitute the main informational resource; there is convergence, both regarding information needs and behavior in searching the information that is of interest to the entities.
\end{abstract}

\section{Keywords}

Opinion making; Information sources; Representative institutions; Information management.
O presente artigo refere-se à busca da informação tal como ela se processa no contexto de entidades representativas, em sua qualidade de formadoras de opinião. Baseia-se em tese de doutorado defendida no Departamento de Ciência da Informação e Documentação da Universidade de Brasília.

Grosso modo, o problema caracterizado como objeto do estudo é o do acesso à informação diante do fenômeno da explosão da informação, tal como vivenciado no contexto de entidades que representam setores e categorias da sociedade brasileira.

Algumas constatações funcionaram como motivação para a pesquisa. Considerou-se primeiramente a importância da opinião na sociedade democrática como fator de mobilização e de busca por mudanças que tanto possam beneficiar a população em seu todo, como atender a segmentos específicos. Considerou-se também que a formação de opinião não constitui uma função exclusiva da mídia, isto é, que a sociedade possui outros mecanismos de expressão, como é o caso das entidades representativas, que, ao defender categorias ou interesses determinados, são também formadoras de opinião.

Trata-se evidentemente de um universo amplo e diversificado, na medida em que são diversificados - e por vezes conflitantes - os interesses a serem representados na sociedade. Observa-se, por outro lado, que, com toda essa diversidade, as entidades possuem uma forma de atuação que se resume basicamente em cinco linhas de ação: 1) lobby junto ao Congresso; 2) presença na mídia; 3) promoção de debates; 4) publicação de pesquisas e trabalhos técnicos; 5) acompanhamento da concorrência.

A entidade representativa tem necessidade de formar uma opinião que é ao mesmo tempo informada e direcionada. Informada, porque precisa dar fundamentação consistente e, com isso, legitimidade a seus próprios argumentos; direcionada na medida em que procura conquistar adesões em três níveis distintos, a saber: 1) adesão dos indivíduos representados (já que algumas categorias são bastante numerosas, sendo difícil um consenso); 2) adesão de outros setores (o que lhes aumenta o poder de reivindicação e negociação); 3) adesão do poder público (a qual lhes aumenta a probabilidade de êxito). 
A informação que irá subsidiar pesquisas, debates, trabalhos, pareceres é, por sua vez, bastante variável, tanto em termos de conteúdo como em relação ao tempo de validade. E o acesso contínuo a toda essa gama de informações apresenta um grau variável de dificuldade, tanto em função da própria disponibilidade da informação que se busca, como dos recursos existentes para encontrála. São dificuldades comuns nos ambientes de trabalho, onde, ao contrário do que sugere a propaganda, nem todas as informações se encontram automaticamente disponíveis para todos. Essa idéia parece inclusive ser fruto do próprio fenômeno da explosão da informação e dos avanços tecnológicos da atualidade. O que se observa ainda, em muitos casos, é a situação característica do acúmulo de papéis coexistindo com computadores de última geração e a informação, propriamente dita, fluindo de forma mais ou menos independente.

Para a entidade representativa, a informação constitui recurso estratégico com o qual irá exercer sua influência. Não é, portanto, algo preexistente e gratuito, mas um recurso com o qual precisa contar para atender objetivos institucionais estabelecidos. Por isso é, também e sobretudo, algo a ser gerenciado em proveito da organização.

A partir do contato com pessoas e entidades e diante de algumas dificuldades apontadas, a pesquisa teve como tema a busca da informação por parte de entidades representativas enquanto formadoras de opinião, sendo o seu objetivo geral identificar necessidades informacionais dessas entidades, considerando-se a importância da informação como subsídio indispensável para as linhas de ação adotadas. De forma mais específica, buscou-se também identificar o tipo de informação que é buscada por formadores de opinião que atuam nas entidades, observar se há um padrão na busca dessa informação, identificar formas de acesso à informação, verificar a facilidade de acesso às fontes utilizadas, verificar a necessidade de serviços especializados.

Para compor a amostra da pesquisa, selecionou-se um grupo de nove entidades representativas dos seguintes setores: indústria, setor bancário, educação, trabalhadores, sindicatos, mulheres, cultura negra e consumidores (quadro 1).
QUADRO 1

Entidades estudadas e respectivos interesses

\begin{tabular}{ll}
\hline Entidade & Interesses representados \\
\hline EA & Funcionalismo do setor bancário \\
EB & Entidades sindicais \\
EC & Indústria \\
ED & Trabalhadores \\
EE & Entidades da sociedade civil organizada \\
EF & Mulheres \\
EG & Ensino superior \\
EH & Cultura negra \\
EI & Consumidor \\
\hline
\end{tabular}

Essas entidades foram selecionadas aleatoriamente a partir de critérios prévios para a delimitação do universo, os quais levaram em conta as seguintes características: caráter permanente; abrangência nacional; representatividade; mediação entre a sociedade e o poder público; formação de opinião. A identidade das entidades respondentes foi preservada em função do objetivo da pesquisa, que não era o de estudar um caso ou casos específicos que pudessem dar margem a comparações indevidas, porém, como exposto anteriormente, o de identificar necessidades e processos envolvidos na busca por informação.

A literatura mostra que esse é um assunto praticamente inexplorado no âmbito da ciência da informação, na medida em que a informação destinada à formação de opinião constitui um objeto de estudo mais característico das áreas de jornalismo e comunicação. Procurou-se então construir um referencial teórico que contemplasse três aspectos: primeiramente, a caracterização da opinião como um processo mental e social; em seguida, a descrição da relação entre opinião e informação; finalmente, procurouse situar a informação como objeto de serviço.

É interessante observar que a maioria dos autores se refere ao processo individual mental e cognitivo da opinião quase que exclusivamente em função da temática da opinião pública. Dentre esses, situa-se Lane (1966) que identifica duas dimensões que o analista da opinião pública usa para descrever uma opinião: direção e intensidade. Ele considera também que as opiniões podem ser personalizadas, quando focalizam os atores, e não os acontecimentos; moralizadoras, quando pretendem que juízos morais influam nas questões; mistificadas quando tendem a sugerir a ação de forças misteriosas, fatos incompreensíveis ou grupos secretos agindo às ocultas. 
Já para Bourdieu (1991), a opinião que é exibida nas primeiras páginas dos jornais sob forma de porcentagens não passa de um artefato cuja função é justamente a de iludir a opinião pública, que, como tal, no seu entender, não existe.

A relação entre opinião e informação não é tão linear ou automática quanto possa parecer, sendo que no Brasil o acesso à informação apresenta uma série de condicionamentos sociais, econômicos e políticos. Para Melo (1990, p. 950), entretanto, "o fundamental é que as opiniões e informações diversas que convivem no conjunto das classes hegemônicas possam se expressar e que veículos que transmitam informações e opiniões das classes que não estão no conjunto das hegemônicas também possam circular livremente."

A informação é, portanto, algo que precisa ser comunicado. Por outro lado, o grande público dos jornais e da televisão se subdivide em públicos menores ou clientelas específicas de acordo com interesses diferenciados, o que parece determinar a necessidade de serviços cada vez mais especializados, principalmente ao se considerar, por exemplo, que o tempo do pesquisador, o tempo do executivo e o do formador de opinião são diferentes para efeito da obtenção da informação desejada. A esse propósito, Lima $(1989,72)$ considera que "o paradoxo da abundância de informações e da impossibilidade de uso efetivo constitui um dos maiores problemas dos serviços de informação." Essa afirmação parece indicar justamente que a tecnologia por si só não constitui garantia de êxito inequívoco para quem busca saber algo específico.

Vários elementos precisam ser compatibilizados, ou seja, é preciso que haja adequação entre recursos existentes e objetivos institucionais, entre quantidade de informação e capacidade de assimilação, bem como entre intenção e utilização. Esses aspectos sugerem, por outro lado, que o profissional da informação tem um papel importante a exercer nas organizações. Nesse pressuposto, Choo (1998) propõe um modelo de gerência da informação a ser desenvolvido a partir de conhecimentos especializados e interdisciplinares e de uma indispensável sensibilidade em relação às demandas do ambiente de trabalho. De acordo com esse modelo, o profissional não se limita a responder perguntas, mas passa a resolver problemas com base na identificação clara de necessidades e usos da informação.

Nas organizações que pretendem formar opinião, exemplificadas pelas nove entidades componentes do estudo, a informação percorre uma série de etapas, desde sua obtenção à sua utilização por parte das pessoas envolvidas (jornalistas, assessores, parlamentares, diretores, executivos e outros). $\mathrm{O}$ que parece claro, no caso, é que, além de servir ao conhecimento e à tomada de decisão, a informação passa a servir obrigatoriamente à formação de opinião, de acordo com os esquemas abaixo:

1) informação $\longrightarrow>$ conhecimento $\longrightarrow>$ opinião $\longrightarrow>$ tomada de decisão

(se processa no ambiente interno)

2) informação-> conhecimento $\longrightarrow>$ tomada de decisão— $>$ formação de opinião

(voltado para o ambiente externo)

Trata-se de uma dinâmica típica de entidades em que a mudança nos cenários de interesse determina continuamente novas e inesperadas necessidades de informação.

A metodologia adotada para levantar tais necessidades e atender os objetivos da pesquisa baseou-se na triangulação de técnicas para coleta de dados. Essa triangulação, oriunda da psicologia organizacional, consiste na utilização complementar de entrevistas informais, questionário e análise documental de relatórios, regimentos e publicações. Segundo Jick (1983), a triangulação apresenta diversas vantagens na medida em que pode ser utilizada não só para se examinar vários aspectos do mesmo fenômeno, como também para proporcionar novos elementos ao entendimento da questão.

O questionário, no caso, foi estruturado em três blocos distintos de perguntas que se referiram a: 1) caracterização da entidade; 2) opinião que deseja formar; 3) informação que precisa obter. Os dados coletados a partir da triangulação revelaram que as nove entidades consultadas constituem efetivamente uma amostra do universo maior da representação de interesses e setores da sociedade brasileira. Têm em média 21 anos de existência, não são governamentais na sua maioria e procuram exercer influência principalmente em áreas como emprego, meio ambiente e direitos humanos. As informações que procuram, embora bastante diversificadas em função dos objetivos específicos de cada uma, enquadram-se basicamente nos seguintes tipos: informação legislativa; informação política; informação econômica.

Ficou evidenciado, entre outros aspectos, o seguinte: para as entidades representativas as fontes impressas são tão importantes quanto a Internet; em que pese a atividade de lobby exercida pela maioria delas, a comunicação 
informal não constitui a principal fonte de informação; existem convergências tanto em termos de necessidades, como de comportamento na busca da informação.

Para as entidades, a tecnologia representa eficácia e status. Por outro lado, é também percebida como fator de dificuldade, na medida em que é associada a constantes gastos e a necessidades de treinamento. É curioso observar que, mais do que a escassez, o excesso de informação constitui fator de dificuldade, contribuindo por vezes ao estresse e ao prejuízo competitivo na organização.

Além dessas conclusões pontuais, constatou-se ainda que as entidades representativas tendem a se perceber mais como produtoras do que propriamente como usuárias da informação. Essa percepção se reflete na própria forma de atuação, a qual inclui a publicação de textos informativos e promocionais que têm como função dar-lhes visibilidade em relação às causas que defendem. Por outro lado, é essa mesma forma de atuação que as converte em grandes consumidoras de um certo tipo de informação cujo efeito se faz sentir a curto e médio prazo na vida dos cidadãos.

Questões referentes a emprego, salário, degradação do meio ambiente e repercussões da globalização na economia do país são apenas alguns dos inúmeros exemplos dos assuntos atuais que, a par de gerarem informações de interesse geral da sociedade, geram também informações específicas e setorizadas, as quais são canalizadas pelas entidades para servir não só como base para seu posicionamento diante das questões, mas também como uma espécie de matériaprima com a qual trabalham para formar opiniões. A esse propósito, a literatura consultada não deixa dúvidas quanto à estreita vinculação entre informação e cidadania.

O contínuo trabalho de busca por informação diversificada e muitas vezes de utilidade efêmera parece indicar a necessidade de terceirização de certos serviços e de consultorias que possam contribuir à melhor gerência da informação, tendo em vista o objetivo último de cada entidade.

A partir dos resultados obtidos e das conclusões possibilitadas pelo estudo, considerou-se como contribuições da pesquisa: trazer a discussão da informação destinada a formar opinião para o âmbito da ciência da informação; contribuir ao entendimento da relação entre opinião e informação no contexto dos interesses específicos representados por entidades; contribuir ao entendimento de que, tal como ocorre em outros ambientes, nas entidades representativas a informação é um recurso a ser gerenciado em função dos objetivos de cada instituição; fornecer elementos para que as entidades formadoras de opinião tenham melhor conhecimento das próprias necessidades de informação.

A pesquisa teve também limitações. A primeira delas se refere à escassez de literatura sobre o assunto. É reduzida a bibliografia referente a entidades representativas, as quais são consideradas na maioria dos casos como grupos de pressão ou de lobby. O estudo de um conjunto de entidades que, embora apresentando características comuns, são diferentes entre si, impôs também limitações em relação ao aprofundamento de alguns aspectos que poderiam eventualmente precisar o tipo de serviço ou administração de recursos que seria mais adequado a determinado caso.

Sugeriu-se finalmente que: futuros estudos possam contribuir ao entendimento de que a gerência da informação não deve permanecer como atividade periférica no âmbito das entidades representativas, mas como atividade central, integrada às instâncias decisoras, em função dos objetivos da instituição; procure-se verificar o papel a ser desempenhado pelo profissional da informação como elemento chave na consecução dos objetivos finais da entidade formadora de opinião; a partir da particularização de casos, busque-se verificar o impacto da informação em termos de usos e conseqüências; busque-se caracterizar situações em que a terceirização de serviços, ou a parceria na criação e utilização de recursos informacionais se constituam em soluções adequadas para a gerência da informação.

\section{REFERÊNCIAS BIBLIOGRÁFICAS}

BOURDIEU, Pierre. L'opinion publique n'existe pas: problèmes politiques et sociaux. Paris : La Documentation Française, 1991. (Democratie et sondages dópinion, n. 666).

$\mathrm{CHOO}$, Chan Wei. Information management for the intelligent organization: the art of scanning the environment. 2. ed. Medford, NJ : Information Today, 1988 (ASIS Monograph Series).

JICK, Todd D. Mixing qualitative and quantitative methods: triangulation in action. In: VAN MAANEN, John. (Ed.). Qualitative methodology, Newburg Park, CA : Sage Publications, 1983, p. 135-148.

LANE, Robert Edwards. A opinião pública. Rio de Janeiro : Zahar, 1966.

LIMA, Ricardo Montenegro de. Estudos de usuários de sistemas de informação: contribuição metodológica de epidemiologia. Ciência da Informação, Brasília, v. 18 n. 2, p. 103-119, jul./dez. 1989.

MELO, José Marques de; SILVA, Carlos Eduardo Lino de. Sociedade civil: direito à informação e direito de opinião. Ciência e Cultura, v. 42, n. 11, p 950-953, nov. 1990. 